\title{
A Personality Based Design Approach Using Subgroup Discovery
}

\author{
Kay Behrenbruch ${ }^{1}$, Martin Atzmüller ${ }^{2}$, Christoph Evers ${ }^{3}$, \\ Ludger Schmidt ${ }^{1}$, Gerd Stumme ${ }^{2}$, and Kurt Geihs ${ }^{3}$ \\ ${ }^{1}$ University of Kassel, Human-Machine Systems Engineering, Mönchebergstr. 7 \\ ${ }^{2}$ University of Kassel, Knowledge and Data-Engineering, Wilhelmshöher Allee 73 \\ ${ }^{3}$ University of Kassel, Distributed Systems, Wilhelmshöher Allee 73 \\ 34125 Kassel, Germany \\ $\{$ K.Behrenbruch, L.Schmidt, Evers, Geihs\}@uni-kassel.de, \\ \{Atzmueller, Stumme\} @cs. uni-kassel.de
}

\begin{abstract}
To facilitate user-centered software engineering, developers need an easy to grasp understanding of the user. The use of personas helps to keep specific user needs in mind during the design process. Technology acceptance is of particular interest for the design of innovative applications previously unknown to potential users. Therefore, our research focuses on defining a typology of relevant user characteristics with respect to technology acceptance and transferring those findings to the description of personas. The presented work focuses on the statistical relationship between technology acceptance and personality. We apply sub-group discovery as a statistical tool. Based on the statistically derived subgroups and patterns we define the mentioned personas to help developers to understand different forms of technology acceptance. By integrating the specifically defined personas into existing methods in the field of software engineering the feasibility of the presented approach is demonstrated.
\end{abstract}

Keywords: Technology Acceptance, Personality, Software Engineering, Usercentered Design, Subgroup Discovery.

\section{Introduction}

Research in the field of Human-Computer-Interaction (HCI) generates models concerning technology acceptance. Those models provide determinants of technology acceptance and explain the causal relation between these determinants. This knowledge from HCI-research is potentially helpful for software-development, but stays isolated from day-to-day praxis of software engineering - mainly because the information is pegged into abstract und theoretical frameworks. In this paper we bridge the gap between theory and praxis by transferring our empirical findings to the textual description of personas [5] that combine personality traits with the determinants of technology acceptance. We use the approved structure of theoretical frameworks as a guideline to implement our findings in the description of personas. A 
persona is a representation of the goals and behavior of a hypothesized group of users. Personas are described in a narrative text that includes behavior patterns, goals, skills, attitudes, and environment. Fictive but characterizing personal details are added to make the persona a realistic character [16]. We propose ways to methodologically integrate the personas in software engineering, namely the agile method SCRUM.

To design personas we use data mining techniques, i.e. sub-group discovery and analysis within the framework of the Technology Acceptance Model (TAM) [6]. The data basis for the statistics is the evaluation of a prototype of an innovative application called Meet- $U$ with the potential target group of the application. The evaluation is based on a questionnaire that contains items to acquire the determinants of TAM and the personality traits taken from the Five Factor Model (FFM) of personality psychology [12]. FFM encompasses five personality traits: extraversion, agreeableness, conscientiousness, openness to new experience, and emotional stability. Subgroup discovery is conducted with the aim to define subgroups with high impact on technology acceptance. Groups are defined by the characteristics of personality traits in correspondence with Perceived Usefulness (PU), Perceived Ease of Use (PEOU), and Intention to Use (IU) taken from TAM. The focus lies on the potential accepters and rejecters of the application. By this, valuable insight concerning those who will be most likely and most unlikely to accept their design is derived. A specific configuration of personality traits in combination with PU and PEOU reveals the types of potential users with respect to technology acceptance. With this knowledge, software-developers are able to search specifically for solutions that will convince skeptics to accept the application while keeping in mind the interests of likely accepters. The following section explains the theoretical background of the presented approach in detail.

\section{Theoretical Background}

In recent years the effect of personality on technology acceptance has been demonstrated by various authors. Especially, the use of social networks has been a major focus of research activity [2,11,13]. Another field of attention has been personality in acceptance of mobile commerce [1,22]. Many aspects of personality were considered in HCI-research such as innovativeness [1,14], need for recognition and sociability [11], computer anxiety [15], computer self-efficiency [7,15], resistance to change $[14,15]$, and interest in the application domain [18]. The most important characterization of personality is FFM [2,7,11,13,14,18,22].

In many cases structural models were generated. Those models determine causal architectures that combine general personality traits with usage and/or intention to use. A direct causal link from personality to usage/intention is an exception to the rule [1]. In most models the influence of personality on usage/intention is mediated by PU and PEOU as determinants of TAM [7,15,18,22]. TAM was chosen as the theoretical framework of this study because it is the most influential and generally accepted-model 
in information science concerning acceptance [17,20]. Within TAM the Intention to Use (IU) the technology is influenced by two beliefs of the potential user concerning usage: PU and PEOU. In this paper, we combine TAM with the - in the context of technology acceptance - frequently used Five Factor Model (FFM) of personality psychology. FFM is a well-accepted instrument to grasp general personality [12]. We use the Theory of Reasoned Action (TRA) [8] to integrate FFM with TAM. TRA explains behavior in general and was used as a matrix in the development of TAM [6]. TRA states that personality traits are external variables and affect the beliefs that are important to the behavior in question [8]. Regarding the use of information technology we assume that the five personality traits of FFM have a direct influence on the beliefs PU and PEOU and that the influence of personality on behavior is moderated by PU and PEOU (see Fig. 1).

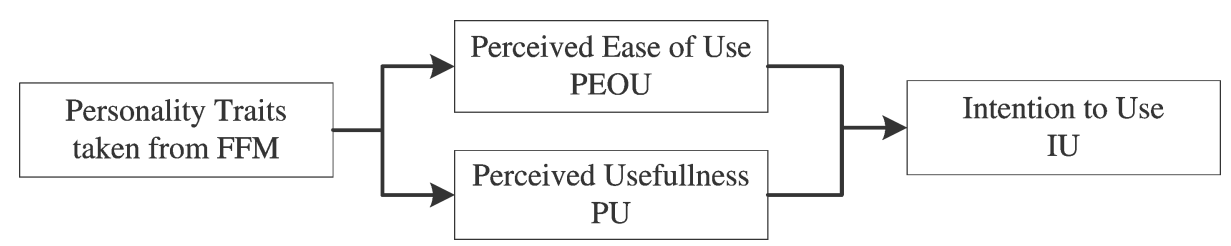

Fig. 1. Integration of the Technology Acceptance Model (TAM) with the Five Factor Model (FFM) in compliance with the Theory of Reasoned Action (TRA)

Authors $[7,18]$ report a significant influence of personality traits directly on PEOU and PU. Authors [18] identify a significant correlation between PU, PEOU and IU with extraversion and agreeableness. Moreover, a significant correlation of PU and PEOU with openness to new experience was reported. In addition a significant correlation for PEOU and emotional stability is indicated [18]. All listed correlation coefficients are lower than 0.21 . The significant correlations of emotional stability, openness and agreeableness with PU [7] do not succeed this value either. In fact, none of the articles cited in this chapter found strong correlations $(>0.5)$ of personality factors to constructs used in models for technology acceptance. Even moderate correlations $(>0.3)$ are very rare. Against this background several structural models were constructed that combine different constructs to explain behavior. Structural models display complex networks of relationships that are no more than interesting to practitioners. They lack a direct link to development praxis and stay abstract and theoretical in their nature. In the following section we present a concretization to those models that bears in mind the needs of software-developers. We suppose that correlation coefficients or structural models alone are not handy and convincing enough to find their way into practice. The presented approach, based on the definition of personas [16], connects research results with common design methods in the field of software engineering and user-centered design. 


\section{$3 \quad$ Empirical Study and Statistics}

We conducted an evaluation of a prototype that supports mobile social networks, group interaction and mobility, called Meet-U [4]. Meet-U is a mobile application for Android devices that is still under development and is designed for the group of 20- to 35-year-olds. Meet-U supports its users in organizing meetings with friends at events. Events can be public or private happenings like concerts or parties. The application helps to plan the event, navigate the user to the event, and supports the user at the event itself. Meet-U proposes events to the users that fit their individual interests as well as their personal calendars. The application suggests means of transport and informs about possible delays, e.g. when using public transport. At the event, information concerning the location, the program, and tickets can be retrieved from automatically integrated services. If desired by the user Meet-U is able to suggest new friends based on the user's settings and interests.

We evaluated Meet-U with the potential user group (157 students, 68 female, 89 male, age 19-37). Participants were given basic information about the prototype in form of a presentation. Next, they were asked to perform tasks with the prototype: compiling a profile, finding and confirming friends, creating an event, searching an event, and being navigated to the event. Subsequently, they filled in a questionnaire. The questionnaire contains items concerning PU, PEOU, and BI taken from [19] as well as the five personality traits of FFM taken from [9]. The questionnaire uses a nine-point Likert-Scale reaching from "strongly agree" to "strongly disagree".

The data from the nine-point Likert-Scale was used to build three categories: high, medium, low. Boundaries of the three categories were defined for each construct individually. Therefore we identified first quartile and third quartile for each construct. By this we were able to define equally distributed categories for each construct. We compared our data for FFM with standard values [9] to assure that there are no particularities in our sample that will cause the relative classification with quartiles to be unrealistic for standard values.

The data abstraction (mapping nine levels to three nominal categories) was conducted for applying subgroup discovery and analysis on the pre-processed data. We applied semi-automatic subgroup discovery for the characterization of "acceptance groups" according to the given data. In general, subgroup discovery [21] aims at identifying interesting patterns with respect to a given target property of interest (e.g., "Accepter"). The method is especially suited for identifying local patterns in the data that only hold for specific subsets. It can automatically uncover hidden relations captured in small subgroups, for which variables are only significantly correlated in these subgroups. We can discover, for example, the subgroup defined by "conscientiousness=low AND PU=high" for the target concept "Accepter" in Table 1. The quality of the subgroup is determined by the lift factor, which measures the target share in the subgroup relative to the target share in the whole data. Thus, a lift of 2 indicates an improvement of the target in the subgroup by $100 \%$. Additionally, we tested the significance using a four-field chi-square test. We applied the open-source VIKAMINE [3] software for discovering interesting subgroups: The automatic component provided several hypotheses, which could then be semi-automatically refined, evaluated and validated. 


\section{Results: Subgroups and Personas}

The results of the subgroup discovery are displayed in Table 1 . We selected the four subgroups with highest relevance for technology acceptance. Relevance was defined by the lift factor $(>2)$ and the subgroup size ( $>10 \%$ of the sample). Two subgroups are indicated as accepters and two as rejecters. Subgroup size, lift factors, and significances are displayed for each subgroup. Each subgroup combines personality factors with TAM beliefs. All defined subgroups are significant at least on a level of 0.05 .

Table 1. Subgroups concerning technology acceptance and personality

\begin{tabular}{llll}
\hline Subgroup & Subgroup Size & Lift Factor & Significance \\
\hline Accepter 1 & 17 & 2.0 & $\mathrm{p}<=0.01$ \\
Accepter 2 & 16 & 2.2 & $\mathrm{p}<=0.001$ \\
Rejecter 1 & 16 & 2.0 & $\mathrm{p}<=0.05$ \\
Rejecter 2 & 16 & 2.4 & $\mathrm{p}<=0.001$ \\
\hline
\end{tabular}

Subsequently the statistical findings of Table 1 were implemented in four personas. Table 2 shows a selection of phrases that can be used to transfer high and low manifestations of the big five personality traits to the description of personas.

Table 2. Phrases to describe Persona with extreme occurrence of Personality Factors

\begin{tabular}{|c|c|c|}
\hline Personality Factors & Positive occurrence & Negative occurrence \\
\hline $\begin{array}{l}\text { Openness to } \\
\text { experience }\end{array}$ & $\begin{array}{l}\text { appreciation of art, inventive, } \\
\text { creative, curious, sensitive to } \\
\text { beauty, aware of feelings }\end{array}$ & $\begin{array}{l}\text { not cautious, plain, } \\
\text { straightforward, not subtle, } \\
\text { bad imagination, uninspired }\end{array}$ \\
\hline Conscientiousness & $\begin{array}{l}\text { organized, efficient, show } \\
\text { self-discipline, act dutifully, } \\
\text { always prepared, exact }\end{array}$ & $\begin{array}{l}\text { easy-going, careless, } \\
\text { unobserving, act } \\
\text { unconcerned, shirk something }\end{array}$ \\
\hline Extraversion & $\begin{array}{l}\text { energetic, show positive } \\
\text { emotions, full of energy, } \\
\text { enthusiastic, action-oriented }\end{array}$ & $\begin{array}{l}\text { solitary, be reserved, seem } \\
\text { quiet, keep in the background, } \\
\text { withdrawn, distant }\end{array}$ \\
\hline Agreeableness & $\begin{array}{l}\text { friendly, compassionate, } \\
\text { cooperative, friendly, } \\
\text { helpful, generous, optimistic }\end{array}$ & $\begin{array}{l}\text { antagonistic towards others, } \\
\text { self-interested, unfriendly, } \\
\text { uncooperative, abusive }\end{array}$ \\
\hline Emotional stability & $\begin{array}{l}\text { calm, even-tempered, secure, } \\
\text { confident, not easily upset, no } \\
\text { persistent negative feelings }\end{array}$ & $\begin{array}{l}\text { sensitive, nervous, unpleasant } \\
\text { feeling, anxious, depressive, } \\
\text { vulnerable, worried }\end{array}$ \\
\hline
\end{tabular}

The personas are meant to guide designers in the process of user-centred design. Sex of the personas was determined freely because no significant relation of sex with technology acceptance was found.

\section{Accepter 1: Conscientiousness Low and PU High}

Michael is 24 years old. He is still living at his parent's home. He studies economics and takes his time. At the moment he should learn for a written exam but he lost the 
records and decided to take the exam next year. He tested the new pro-totype. Michael likes that Meet-U helps him to organize things. Often he forgets about dates, misses the train, or forgets to call people when he is late. He hopes Meet-U will help him without much effort from his side.

\section{Accepter 2: Emotional Stability High and PEOU High}

Cindy is a 19-year-old who just moved into town and started her studies at the university. She takes courses in psychology but is not quite sure if she will stick to this field of study. She liked high-school a lot but the change and the new situation are also nice. At the moment she is satisfied with exploring campus and university, and making new friends. She participated at the test of Meet-U and plans to download the newest version now. She just finished learning for the first exams and thinks the application will help her to have a good time with interesting events now.

\section{Rejecter 1: Emotional Stability Low and PEOU Low}

Martha is 31 years old and is afraid that she will not be able to pass her last exams to finish her studies in social work. Her mother says she does not mind her taking more time but Martha feels guilty not to be able to make her own living at her age. She participated in the evaluation of Meet-U. When she was told about the features of Meet-U she hoped that Meet-U might help her to meet people despite her shyness. But when she had to perform the tasks with Meet-U she was irritated. To her the application seems much more complicated than the others say.

\section{Rejecter 2: Agreeableness Low and PU Low}

Frank is 24 years old and studies chemistry. His girlfriend just moved into his flat and he likes her to be around. She makes him feel good - and also she is much better at cleaning the house than he ever has been. Frank is at home and tells his girlfriend about the evaluation of Meet-U he participated in: "Why should I organize thinks for those who are not able to get along by themselves. I know that I want to go out with you and which places I like. Why should I give all my personal data to Meet-U when there is no use to it."

\section{$5 \quad$ Methodological Integration}

Personas are a part of user-centered design [5,16]. Often they are used in scenarios that help to describe and explain the context of use. This kind of scenario is part of the process of analyzing the context of use and defining user-requirements. We suggest applying the personas also in the process of implementation of software. The agile software engineering method SCRUM incorporates user stories. Those stories are actually a list of requirements, normally in the form of: "As a <user type $>$ I want to $<$ do some action $>$ so that $<$ desired result $>$ ". We propose substantiating the $<$ user type $>$ to a persona. There should be a set of personas well-known to the whole development team. The personas give the team a vivid impression of people, who should use their system. The personas should act as a symbol for or connection to knowledge about the potential users of the system. With respect to technology acceptance and the definition of personas in this paper, the development team will be able to keep in mind the issue of acceptance by being confronted with the personas. In 
the case of Meet-U question like this arise: "I don't think we should make this dialogue too complex. Martha will be afraid and will give up." It is in the responsibility of the product owner (a role in SCRUM) to decide which persona is the right one for which user-story. In the present case the product owner should be familiar with the issue of technology acceptance.

In addition to that, SCRUM is designed to provide executable software throughout the whole design-process. This feature opens up possibilities to meet the following needs to foster technology acceptance in the development process of innovative applications. We are arguing to intensify the iteration of evaluation in the case of the development with regard to uncertain technology acceptance. Therefore we propose to evaluate partially functional prototypes parallel to programming software. Each sprint of SCRUM provides this kind of prototypes as executable software. Evaluation parallel to programming needs to be fast and flexible. This is why we suppose to let the partially functional prototypes be evaluated by usability experts instead of real users. Experts use inspection methods to check for usability problems and are able to provide results much faster. To incorporate the user's view on technology acceptance the evaluating experts should also be familiar with the personas used in SCRUM. The feedback of the evaluation results to the developers is ensured by the participation of the usability experts in the sprint planning meeting that is done on a regular bases in SCRUM.

\section{Outlook}

This paper presents an approach to transfer research findings from HCI-research on technology acceptance and personality to development-practice. We present ongoing research of an empirical study in the context of methodological reflections. At the present stage it is not possible to provide an approved set of personas. Within the VENUS project (http://www.uni-kassel.de/eecs/iteg/venus/) data is currently gathered for technology acceptance and personality traits in two other development projects. The objective is to generalize the statistical findings for Meet-U with respect to different application properties and to other user groups. At the same time we apply the presented methodological integration in three different development-projects and are gaining new insights to further improve it for practical application. The integration of personas to user-centered design and software engineering proved to be a targetaimed approach. The evaluation of partially functional prototypes parallel to the implementation of software is a vital part of the ongoing work and was applied successfully. A major topic of future research will be to approve the effectiveness of the presented approach related to agile software engineering.

Acknowledgments. We thank Hesse's Ministry of Higher Education, Research, and the Arts for funding VENUS as part of the research funding program "LOEWE Landes-Offensive zur Entwicklung Wissenschaftlich-ökonomischer Exzellenz”.

\section{References}

1. Aldás-Manzano, J., Ruiz-Mafé, C., Sanz-Blas, S.: Exploring individual personality factors as drivers of M-shopping acceptance. Industrial Management \& Data Systems 109(6), 739-757 (2006) 
2. Amichai-Hamburger, Y., Vinitzky, G.: Social network use and personality. Computers in Human Behavior 26(6), 1289-1295 (2010)

3. Atzmueller, M., Puppe, F.: Semi-Automatic Visual Subgroup Mining using VIKAMINE. Journal of Universal Computer Science (JUCS), Special Issue on Visual Data Mining 11(11), 1752-1765 (2005)

4. Comes, D., Evers, C., Geihs, K., Saur, D., Witsch, A., Zapf, M.: Adaptive Applications are Smart Applications. In: Proceedings of International Workshop on Smart Mobile Applications, San Francisco (2011)

5. Cooper, A.: The Inmates Are Running the Asylum: Why High-tech Products Drive Us Crazy and How to Restore the Sanity. Sams, Indianapolis (2004)

6. Davis, F.D., Bagozzi, R.P., Warshaw, P.R.: User Acceptance of Computer Technology: A Comparison of Two Theoretical Models. Management Science 35(8), 982-1003 (1989)

7. Devaraj, S., Easley, R.F., Crant, J.M.: Research Note-How Does Personality Matter? Relating the Five-Factor Model to Technology Acceptance and Use. Information Systems Research 19(1), 93-105 (2008)

8. Fishbein, M., Ajzen, I.: Belief, Attitude, Intention and Behaviour: An Introduction to Theory and Research. Addison-Wesley (1975)

9. Gosling, S.D., Rentfrow, P.J., Swann, W.B.: A very brief measure of the Big-Five personality domains. Journal of Research in Personality 37(6), 504-528 (2003)

10. He, Q., Wu, D., Khosla, P.: The quest for personal control over mobile location privacy. IEEE Communications Magazine 42(5), 130-136 (2004)

11. Hughes, D.J., Rowea, M., Batey, M., Lee, A.: A tale of two sites: Twitter vs. Face-book and the personality predictors of social media usage. Computers in Human Behavior 28(2), 561-569 (2012)

12. McAdams, D.P.: Five Factor Model in Personality. Journal of Personality 60(2), 329-361 (1992)

13. Moore, K., McElroy, J.C.: The influence of personality on Facebook usage, wall postings, and regret. Computers in Human Behavior 28(1), 267-274 (2011)

14. Nov, O., Ye, C.: Personality and Technology Acceptance: Personal Innovativeness in IT, Openness and Resistance to Change. In: Proceedings of the 41st Annual Hawaii International Conference on System Sciences, HICSS 2008, p. 448 (2008)

15. Nov, O., Ye, C.: Users' Personality and Perceived Ease of Use of Digital Libraries: The Case for Resistance to Change. Journal of the American Society for Information Science and Technology 59(5), 845-851 (2008)

16. Pruitt, J., Adlin, T.: The persona lifecycle: Keeping people in mind throughout product design. Elsevier, Amsterdam (2006)

17. Schepers, J., Wetzels, M.: A meta-analysis of the technology acceptance model: Investigating subjective norm and moderation effects. Information \& Management 44(1), 90-103 (2007)

18. Svendsen, G.B., Gunnvald, B., Johnsen, K., Almås-Sørensen, L., Vittersø, J.: Personality and technology acceptance: the influence of personality factors on the core constructs of the Technology Acceptance Model. Behaviour \& Information Technology, 1-12 (2011)

19. Venkatesh, V., Gordon, B., Davis, F.: User Acceptance of Information Technology: Toward a Unified View. Management Information Systems 27(3), 425-478 (2010)

20. Venkatesh, V., Davis, F.D.: A Theoretical Extension of the Technology Acceptance Model: Four Longitudinal Field Studies. Management Science 46(2), 186-204 (2000)

21. Wrobel, S.: An Algorithm for Multi-Relational Discovery of Subgroups. In: Proc. 1st European Symposium on Principles of Data Mining and Knowledge Discovery, pp. 78-87 (2007)

22. Zhou, T., Lu, Y.: The Effects of Personality Traits on User Acceptance of Mobile Commerce. International Journal of Human-Computer Interaction 27(6), 545-561 (2011) 